\title{
Economic Cooperation for Common Prosperity in the Trans-Pacific Region ${ }^{1}$
}

\author{
Moon-Soo Chung*
}

\section{Changes in the World Economy and Future Challenges}

As we are well aware, an age of interdependence based on free trade and investment has come to us. With the development of information, telecommunication and transportation technologies, the global market is no longer divided, but is rapidly integrating into a single open market. With the advent of a digitalized and high-technology society, economic activities are being conducted in real time, and competition on a global scale.

Along with the rapid advancement of globalization, regionalization is also fast expanding. As of January 2005, a total of 162 regional trade agreements between geographically proximate or like-minded countries have been established. Still expanding European Union, looming Free Trade Agreement of the Americas and mounting interests for elevating ASEAN+3 into the East Asia Community are also accelerating the emergence of major trading blocs.

This trend of globalization and regionalization presents both opportunities and challenges. The formation of large-scale markets and growth possibilities should be perceived as opportunities for some countries. For other countries that are not prepared, however, globalization brings serious challenges they have never faced before.

\section{Economic Cooperation in the Trans-Pacific Region}

Taking this opportunity, I would like to highlight the significance of the Trans-Pacific economic cooperation in this age of globalization and regionalization. The economic importance of the Trans-Pacific, notably the Asia-Pacific region becomes apparent when we consider the fact that APEC member economies account for as much as half of the world trade and 60 per cent of global GDP. No wonder brisk movements toward bilateral FTAs are under way in this region, besides the already established free trade agreements such as those between Korea and Chile, and the U.S. and Australia, to name a few. Taken

\footnotetext{
${ }^{1}$ This contribution is an edited version of an address given at the New Vision for Trans-Pacific Economic Cooperation Conference held at Inha University on May 302005.

"Professor of Economics, Inha University, Nam Gu, Incheon, Korea. On leave as Advisor to the President for Economic Policy, Republic of Korea
} 
together, these bilateral efforts will contribute to foster a better environment for free trade and investment across the region. For this reason, Asia-Pacific countries need to expedite such dialogues further.

Meanwhile, Trans-Pacific economic stability and prosperity requires concerted efforts among related countries. In this context, harmonized approaches represented by the Bogor Goals should be intensified in the region under the auspices of APEC. Someone may be tempted to regard the aforementioned emerging trading blocs as a threat to building a comprehensive economic cooperation system in the region. I would like to view this issue the other way around. APEC can be utilized as a vehicle to recognize and alleviate incongruous factors between sub-regional economic bodies, securing harmonized and open regionalism in the whole region. APEC has indeed given member economies valuable opportunities to cope with not only economic but also many human security issues. I hope it will contribute to guaranteeing a peaceful and prosperous future of the entire region. As an APEC chair economy of 2005, Korea will take the lead in reforming the APEC process to enhance its efficiency with an aim to produce substantial results.

\section{Possible Areas for Future Cooperation in the Region}

The question that naturally follows is what indeed could and should be done through joint efforts in this region. Hoping to shed some light on this issue, I want to make brief comments on possible areas for future economic cooperation.

First of all, macroeconomic stability and collaborative, preventive measures for this purpose need to be given more emphasis than before, considering the lessons from the Asian financial crisis in 1997. The ongoing discussions among the ASEAN+3 to deepen and strengthen the current currency swap networks, namely the Chiang Mai Initiative could be a good example of such efforts. We need to enlarge the breadth and depth of financial cooperation in this region not only to address one specific country's vulnerability but also to lessen the spill-over risks arising from growing interdependence among economies nowadays.

Second, Given different levels of economic development and various economic structures of regional economies, the possibility of building a closer industrial cooperation based on individual sectors needs to be exploited. With ever growing intra-industry trade in the global economy, regional division of labor and comparative advantage of each country need to be taken full advantage of, as vast opportunity of outsourcing is becoming increasingly available.

Third, with many countries in this region emerging as a growth engine for the global economy, securing stable energy supply has become a vital issue. Therefore, closer dialogues and cooperation on bilateral and multilateral levels between energy-sufficient and deficient countries deserve more attention than ever, in view of high oil and 
commodity prices which are likely to continue for some time.

Last but not least, harmonized efforts should be made to reduce the gulf between the rich and the poor economies in the region. Cooperation for increasing economic and technical assistance to less developed countries, concerted efforts towards minimizing the digital divide across the region, and extended contribution to the Millennium Development Goals (MDG) can pave the way for common prosperity of the region. The swift and massive assistance from the international community following the devastating tsunami in South-East Asia of December 2004 has not only served the humanitarian cause, but also contributed to significantly reducing adverse impacts on those people in poverty.

\section{Korea's Role for Regional Economic Cooperation}

Let me add a few words about Korea's role toward strengthening economic cooperation in the Trans-Pacific region. Over the past decades, Korea has made remarkable strides in economic development and reform. Now, Korea can share valuable lessons it has learned from this process and can help foster cooperation between advanced industrial countries and developing countries in this region. As a viable facilitator, Korea is aspiring to transform itself into the business hub, namely a financial and a logistics hub of Northeast Asia. In this regard, we have high stakes in garnering economic benefits from freer trade and investment, not to mention the enhanced peace and security across the region.

As you know, APEC members are Korea's major trading and investment partners, with 70 per cent of Korea's total trade and 63 per cent of foreign direct investment in Korea generated by the APEC community. Granted, our efforts toward multiple FTAs are mainly focused on the Trans-Pacific regional economies, ranging from Chile to China, Japan and the ASEAN, and to the U.S and Canada. Through these efforts, we hope to contribute to ensuring business friendly environment across the whole region as well as seek mutual benefits with our trading partners.

No doubt you are all aware, Korea has been an integral part of APEC from its very beginning in 1989. APEC 2005 is expected to be more meaningful than the previous ones for two reasons. First, APEC is to undertake a mid-term stocktaking this year to assess its progress towards the Bogor goal, which will renew members' commitment to this overarching goal. Second, being held shortly before the 6th WTO Ministerial Meeting in mid-December in Hong Kong, the APEC Economic Leaders' Meeting would be a useful setting to generate an important momentum for the success of the WTO process under the Doha Development Agenda. Under the theme of APEC 2005, 'Towards One Community: Meet the Challenge, Make the Change", the Korean government, as the chair economy, will make its utmost efforts to make meaningful and substantial steps towards building a peaceful and prosperous Asia-Pacific community. 


\section{Closing Remarks}

Economic cooperation and common prosperity in the Trans-Pacific region can be attained only through concerted efforts of all countries in the region. Korea will continue to maintain its strong commitments to this end. I am confident that the establishment of peace and prosperity in this region will be a driving force in gearing up the global economy and promoting the world peace in this age of globalization. In closing, I hope this conference will serve as an occasion where participants can share insights for ways to enhance regional economic cooperation for common prosperity. 